\title{
Sanat Eserlerinin Yaratılma Süreci
}

\section{Aydın GÖRMEZ* ve Merve KARAKUŞ**}

Öz: İyiye ve güzele ulaşma arzusu geçmişten günümüze kadar devam edegelen evrensel bir olgudur. Tarih boyunca yaşanan savaşlar, salgınlar, deprem ve sel gibi doğal felaketler ve özellikle Sanayi Devrimi ile birlikte ortaya çıkan kargaşa ortamı, yaşamın sıkıcılığı ve ruhsuzluğu bireyi bunaltmıştır. Nefes alma ihtiyacı içinde olan birey bu gereksinimini, bilinçli veya bilinçsiz, kendisinde çeşitli duygular uyandıran güzel sanat dallarında ortaya konulmuş eserler yolu ile gidermeye çalışmıştır. Bu sebeple, insanla beraber büyüyüp gelişen sanat, insan yaşamının gerekliliklerinden bir tanesi haline gelmiştir. Bütün bunlar olup biterken Yunan filozof Eflatun ile başlayan sanatın işlevi, toplum için mi, sanat için mi olduğu türden tartışmalar halen devam etmektedir. Öte taraftan sanat eserlerinin üretilme sürecinde sanatçının duygu dünyasında yaşananlar da gizemini koruyarak başka bir tartışma konusu olmuştur. $\mathrm{Bu}$ çalışmada, sanatın hangi ihtiyaçlar doğrultusunda doğduğu, hangi süreçlerden geçtiği ve yorumlanmasında ortaya çıkan bireysel farklılıkların incelenmesi amaçlanmaktadır.

Anahtar kelimeler:Sinir bilim, sanat, sanatçı, sanat eseri, nöroestetik

\section{The Process of Creation of Art}

Abstract: The desire to achieve the good and the beautiful is a universal phenomenon that goes on from the past to the present. Throughout history, wars, epidemics, such natural disasters as earthquakes and floods, and particularly the turmoil, boredom and soullessness of life that emerged with the Industrial Revolution have overwhelmed humanity. Human beings, left breathless, have tried to fulfil this need, consciously or unconsciously, employing works created in fine art that evoke various emotions in them. For this reason, art, growing and developing with people, has become one of the requirements of human life. Meanwhile, the debates starting with the Greek philosopher Plato, such as the function of art, or whether it is for the sake of art

\footnotetext{
* Doç. Dr. Van Yüzüncü Y1l Üniversitesi, Edebiyat Fakültesi, İngiliz Dili ve Edebiyatı Bölümü, Email: aydingormez@hotmail.comOrcid No:

${ }^{* *}$ Yüksek Lisans Öğrencisi, Van Yüzüncü Yıl Üniversitesi, Sosyal Bilimler Enstitüsü, Email: mrvkarakus@hotmail.com, Orcid No: 0000-0002-0936-421X.
} 
or society still continue. On the other hand, what happens in the emotional world of the artist during the creation process of the artwork has been another subject of discussion, keeping its mystery. This study aims to examine the reasons for the creation of art, the processes it undergoes and the individual differences in its interpretation.

Keywords: Neuroscience, art, artist, artwork, neuroaesthetics

\section{Giriş}

Öncelikle sanatın ne olduğu, sanatçının kim olduğu, sanatın amacının ne olduğu gibi sanat felsefesi kapsamına giren genel bazı kavram ve tanımlamalar üzerinde durulacaktır. Sanatın tanımını yapmak oldukça zordur. Düşünme becerisi bir tarafa bırakılacak olursa, insanı diğer canlılardan ayıran özelliklerin başında sanat ve estetik konuların olduğu ve bu özelliklerin insana artı değer kazandırdığı ifade edilmektedir (Emre, 2014, s. 22). İnsanın bu amaçla ortaya çıkardığı ürünlerin sanat eseri olarak nitelendirilmesi ve sanatın tanımı hemen her dönemde değişiklikler göstermiştir. Ancak en genel tanımlama ile sanat; bireyin kendisini ifade etme aracıdır. Dil, çizgi ve formlar ise sanatın aktarılma şekilleridir. Güzel Sanatlar Terimleri Sözlüğ̈̈’nde yer alan tanıma göre sanat: “Bir duygunun, bir tasarının, bir düşüncenin ya da güzelliğin anlatımında kullanılan yöntemlerin tümü ve bunların sonunda erişilen üstün yaratıcılık” (Türk Dil Kurumu). Edebiyat ve Söz Sanatı Terimleri Sözlüğ̈̈’nde ise şu şekilde tanımlanmıştır: "İnsanda estetik duyguyu heyecana getirecek eserler meydana getirme işi”" (Türk Dil Kurumu). Emre’ye göre sanat, insanın aklı ve ruhunun doğaya temas ederek yaptığı soyutlamadır ve insan ruhunun dış dünyayı yumuşatıp beğenilir hale getirilmesidir (Emre, 2014, s. 59). Yansıtma kuramcılarına göre sanat; doğa, insan ve hayatın kendisidir, sanatçı bir ayna tutar gibi bunları yansıtır (Moran, 2012, s. 17). Bu yaklaşıma göre sanatçının duygu dünyası bir kenara atılmıştır. Bu ihmali fark eden romantiklere göre ise sanat duyguların anlatılmasidır (Moran, 2012, s. 101). Bozkurt'un kendi eserinde yer alan Abidin Dino'nun sanatın ne olduğunu tanımladığı cümlelere ilerleyen satırlarda yer verilmiştir:

En küçükten en büyüğe, mikrokosmostan makrokosmosa, atomun iç yapısından uzayın derinliklerine, canlı insan bedeninin dehlizlerinden cansız taş toprağın gizlerine değin sanatların ulaşamadığı, erişemediği bir alan yok gibidir. Çünkü sanatlar, varlığa açılan delici gözler, sanki nesneleri yorumlayan görüş açıları, insanın başını döndüren yorumlama becerileri olarak, hiçbiri ötekine benzemeyen, daha önce varolmamış yepyeni düşüncelere, duygulara, dünyalara açılan pencerelerdir. (Bozkurt, 1994, s. 89) 
Dino tanımlamasını yaparken bile edebî dilden uzaklaşmamıştır. Diğer yandan Tolstoy sanatın öğretilebilir bir şey olmadığını, kendi kendine insanın içinden taşarak geldiğini belirtmiştir (Tolstoy, 2004, s. 75).

Sanatın farklı tanımlamaları olsa da özü bellidir ancak her sanat türünün değişik dişa vurum biçimleri mevcuttur. Bozkurt her sanat dalının kendi dilini yarattığını belirtmiştir (Bozkurt, 1994, s. 94). Her sanat dalının kendi dili olduğu gibi her kültürün ve dönemin de kendi estetik formülü bulunmaktadır. Estetik 18. yüzyılda Alexander Gottlieb tarafından bağımsız bir disiplin haline getirilmiştir. Estetikçiler şu sorulara cevap aramaktadırlar: Bir eserin güzel ya da iyi olması ne anlama gelmektedir? Bu yargılar nesnel ya da öznel midir? Estetik tutuma göre bir sanat eserine bilgi edinmek, herhangi bir çıkar gözetmek ya da eserden fayda sağlamak amacı güderek yaklaşılıyorsa sergilenen tutum estetik değildir. Estetik tutuma uygun olan davranış günlük hayatın kaygılarının dışına çıkıp esere keyif alma amacıyla yaklaşılması ve eserden heyecan, sevinç, hoşlanma gibi hazların alınmasıdır. Estetik tutuma göre iyi bir eser bireyde estetik yaşantı uyandıran eserdir (Moran, 2012, s. 233-234). Ancak günümüzde devam eden tartışmalardan birisi de estetik yargıların nesnel mi yoksa öznel mi olduğu konusudur. Öznelcilere göre iki zıt görüşten biri diğerinden daha doğru değildir. Fakat estetikte nesnel görüşü benimseyenlerin savundukları şeyi tam olarak açıklamak oldukça zordur. Çünkü konuyu açıklamak için genel geçer ölçütler bulunmamaktadır. Moran'a göre ise eserin bazı yanları nesnel bazı yanları öznel sayılabilmektedir (Moran, 2012, s. 321). Genel bir yorumlama ile estetik beğeni insandan insana, toplumdan topluma ve çağdan çağa değişmektedir. İnsandan insana değişen boyutta beyinde renk, çizgi, şekil ve sanat eserlerinin algılanması konularıyla ilgilenen disiplin olan nöroestetik söz sahibidir. Nörolojik boyutunda estetik yargılamanın beynin evrimleşmesi ile başladığı görüşünün yanı sıra, Visual Aesthetic Experience başlıklı makalede yer alan ifadelere göre, bazı antropologlar ilk estetik yargılama formların simetrik ve dengeli olması ve renklerin parlaklığının tecrübe edilmeye başlanması ile hayata girdiği görüşünü benimsemişlerdir. Denge ve düzen hayatın olmazsa olmazı iken, parlaklık ise karanlık karşında insanın kendisini güvende hissetmesidir (Steenberg, 2007, s. 89). Collage Üniversitesi’nden Semir Zeki ve arkadaşlarının yürüttüğü çalışmadan elde edilen bulgulara göre (Vessel, Starr, \& Rubin, 2012, s. 6) beyindeki orbitofrontal bölge birey tarafından güzel olarak tanımlanan manzara, portre ve natürmort gibi görsellere maruz kalınca aktifleşmektedir. Kötü ve çirkin olarak tanımlanan görsellerde ise, aksine, kaçma refleksinin uyarılması için beyindeki motor bölge aktif hale gelmektedir. 
Beyinde konuyla ilgili yetkili bölge olan 'amigdala' duygusal hafiza ve duygusal tepkilerin oluştuğu temel bölgedir. Aynı zamanda korku duygusu başta olmak üzere, duyguların denetiminden sorumludur ve refleksleri artırmak için beynin ilgili bölgelerine uyarı göndermektedir. Amigdala'nın güzellik ile ilgili yargılarda bulunulacağı zaman daha aktif hale geldiği Jacobs ve Comelissen'e ait makalede de yer verilmiştir. Amigdala bölgesi zarar görmüş katılımcılarda, Jacobs ve Comelissen'in teorisine göre, yapılan çalışmalar göstermiştir ki söz konusu özelliklere dikkati yöneltme ve estetik yargılama yapma becerilerinde aksaklık oluşmuştur (Jacobs \& Cornelissen, 2017, s. 4). Özetle fizyolojik boyutta estetik yargılama yukarıda bahsedilen şekilde gerçekleşmektedir.

Sanatçının kim olduğuna gelecek olursak; Pablo Picasso’ya ait olan sanatçı için kullandığı ifadelere, Bozkurt eserinde şu şekilde yer vermiştir:

Bir sanatçının ne olduğunu sanıyorsunuz? Bir ressamsa gözlerinden, bir müzisyense kulaklarından, bir şairse yüreğinin her telinden hatta bir boksörse pazularından başka şeyi olmayan bir budala mı? Tam tersine, aynı zamanda ister sıkıntıl1, ister acı, ister tatlı olsun bu dünyada ne olup bittiğinin her zaman farkında bir siyasal varlıktır o ve bu olaylarla biçimlendirir kendini. (Bozkurt, 1994, s. 22)

Bozkurt'un kendisi de sanatçıyı 'toplum eleştirmeni' olarak tanımlar ve yaşadıkları çağın tanığı, toplumun öncüsü olarak aydın kişinin sorumluluğunu yüklemektedir. Çünkü gerçek aydın bugünün değerleriyle değil geleceğin değerlerine yoğunlaşarak daha iyi bir gelecek kurmanın bilincinde olan kişidir (Bozkurt, 1994, s. 25-26). Gösterim Sanatlart Terimleri Sözlüğü’nde ise sanatçı şu şekilde tanımlamıştır: "Yaratıcı ve olağandışı nitelikleri olan, sanat yapabilecek yetkide olan kişi” (Türk Dil Kurumu). Farklı bir açıdan Tolstoy’a göre; sanatçı, sanat için ağır bir yükün altına girmesi gerekmektedir (Tolstoy, 2004, s. 80). Bu yükten ne kastettiği ise ilerleyen satırlarda şu şekilde ifade edilmiştir: "Sanatçının asıl görevi, çıkarcılıktan kurtulmuş olarak halka inip, kendisine bir yer edinebilmek ve onurlu yaşamanın gereğini yerine getirmektir” (Tolstoy, 2004, s. 81). Tezcan sanatçı olarak doğulmayacağını ancak sanatçı olmak için potansiyel ile doğulacağını belirtmiştir (Tezcan, 2018, s. 169). Sanat hayatta kalmak için gerekli olmamasına rağmen, dünya çapında her dönem ve her topluluk tarafindan icra edilmiştir. Sanata ve sanat eserine hem sanatçının kendisi hem de alıcı ihtiyaç duymaktadır (Kandel, 2012).

Sanatın amacına gelince günümüzden yaklaşık iki milyon yıl önce başlamış ve on bin yıl önce son bulmuş olan Paleotik dönemde mağara duvarlarına yapılan resimler insanlık tarihinin bilinen ilk sanat eserleri olarak nitelendirilmektedirler. Bu resimler genellikle hayvan 
figürlerinden oluşmaktadır ve Fransa'nın güney batısı, İspanya, Afrika ve Anadolu bölgelerinde görülmektedir. Tarih öncesi dönemin en eski ve en uzun süren dönemi olan Paleotik Çağ'da insanlar yaşamlarını toplayıcılık ile sürdürmekteydi. Sanat çok daha sonraki dönemlerde tanımlanıp kavramsallaştırıldığı için, bu dönemde yaşamış insanların amacı bilinçli olarak sanat eseri ortaya koymak değildi. O halde neydi o dönem insanlarının amacı? Bireyin zihni +1 değer kazanmaya başlamasıyla iç dünyasını dışa vurma, o dönem yaşananları mağara duvarlarına aynalama ve yaşadıkları duyguları aktarma ihtiyacı ortaya çıkmıştır. Öz farkındalık, hayal gücü ve geleceği planlama becerileri geliştikçe ilk ürünler ortaya çıkmaya başlamıştır. Geçmişten günümüze hayatımızın bir parçası olan tüm icatlar ihtiyaçlardan doğmuştur. Tehlikeli dış dünya, birlikte yaşayan grupların iletişim ihtiyacı, beslenme ve barınma gibi temel ihtiyaçlar ile başlayan sürece bireyin kendisini ifade etme ihtiyacı başta olmak üzere, dünyayı anlama ve anlamlandırma çabası ve ihtiyacı eklenmiştir. Bütün bu faktörler birlikte düşünüldüğünde insanları sanata iten sebepler daha anlamlı hale gelmektedir. Tezcan ise görüşlerini şu şekilde ifade etmiştir: "İlkel toplumlarda sanat yapıtları, birer süs ya da estetik eşya olmayıp din gibi belli işlevleri karşılar.” (Tezcan, 2018, s. 33). Bir diğer deyişle "Sanatsal obje olmanın ötesinde gelişmekte olan karmaşık ruhani inançların sembolleridir.” (Fagan, 2019, s. 189).

Elbette geçen zamanla birlikte sanatsal ifade git gide zenginleşmiştir. Mağara duvarlarına çizilen resimlerle başlayan süreç renklendirme, kompozisyon, konuyu ayrıntılandırma, soyut çalışmalar olarak devam edegelmiştir. "İzole yaşam bozuldu; farklı gruplar arasında temaslar ve istihbarat alışverişi yoğunlaştı; teknolojik yenilikler gelişti. Zaman içinde, yenilikler sosyal yaşama ve âdetlere de; resim sanatına, müziğe, ve sürekli değişen çetin bir dünyayı tarif eden çetrefilli inançlara da ulaştı” (Fagan, 2019, s. 165). Dünyanın farklı bölgelerinde farklı zamanlarda, özellikle iklim koşullarının etkisiyle, sanatsal gelişim farklılıklar göstermiştir. İnsan var oluşunun her evresinde sanata ihtiyaç duymuştur. Hayvanlar doğal düzenin mahkumudur ancak insan çevresindeki dünyanın farkındadır ve aktif olarak içinde yer aldığı bu düzenden sıyrılabilme becerisine de sahiptir (Bazin, 1998, s. 15). İhtiyaç duyulan bu kaçışlar ile Bazin sanatın temellerinin atıldığına işaret etmiştir. Aynı zamanda Bazin karanlık mağara koşullarında modelsiz resim yapabilmenin güçlüğüne ve ilk sanatçıların güçlü bir hafızaya sahip olduklarına da dikkat çekmiştir (Bazin, 1998, s. 16).

Bazı anlarda zihin şimdiki zamandan kaçarak sınırların olmadığı kendine ait alanda özgürce vakit geçirir. Beynin bu aktivitesi hayal kurmaktır. Hayal kurmanın sınırı yoktur. Hemen her yaşta insan günün herhangi bir vaktinde bilinçli ya da bilinçsiz olarak bu ucsuz bucaksız yolculuğa çıkmaktadır. Bu zihinsel kurgulamayı oluşturma becerisi ise hayal gücüdür. 
Hayal gücü hem sanatçının eserini yaratabilmesi hem de bireylerin gündelik yaşamın ruhsuzluğundan sıyrılabilmesi için gereklidir. Emre, hayal gücünün sanattaki önemini şu şekilde ifade etmektedir: "Hayal gücü olmaksızın hiçbir sanat eseri üretilemez" (Emre, 2014, s. 13). İnsan var olanla yetinen bir varlık değildir. Bedenlerimiz sınırlıdr; fakat sınırların ortadan kalktığı yer beyindir. Hayal kurma yetisinin devreye girmesi ile zaman ve mekan ortadan kalkmaktadır. Bu yüzden sanatçının en büyük yardımcısı hayal kurma becerisidir. Yaratıcı bireyler hayal güçlerini daha uzak geleceklere, mekanlara, bakış açılarına ve varsayımsal gerçeklere kadar genişletebilmektedirler. Nörolojik boyutta beyinlerinin ilgili bölgeleri birbirleriyle iletişime geçerek geçmiş anıları canlandırır veya başkalarının niyetlerini düşünmelerine yardımcı olur (Sheikh, 2019).

Hayal gücünün ürünü olan sanat eserleri de esere maruz kalan bireylerin zihinsel faaliyetlerini aktif hale getirmek gibi dolaylı bir misyon içerisindedirler. Mina Urgan edebî eserlerin bu konu hakkında önemini şu cümleleriyle ifade etmiştir: “... okuyucular, merak ettikleri neredeyse her şeyi -örneğin değişik çevrelerdeki ve ülkelerdeki insanların duygularını ve düşüncelerini, toplumsal sorunları, kişilerin ruhbilimsel incelemelerini, kendi çağlarının ya da geçmişin yaşantısını, heyecan verici serüvenleri ve bunlara benzer en değişik konularıromanlarda bulabilirler" (Urgan, 2018, s. 744).

\section{Sanat Eserinin Oraya Çıkma Süreci}

Dünyada bulunmayı hiçbir canlı seçmemiştir; ancak içinde yaşadığımız kaotik düzenin farkında olan tek canlı insandır. Giriş bölümünde bahsedilen, insanın +1 değer kazanarak farklılaşması beraberinde yaşadığı dünyayı anlama ve anlamlandırma çabasını getirmiştir. Anlama çabası felsefeyi doğururken, anlamlandırma çabası ise sanatın ve daha pek çok toplumsal kavramın ortaya çıkmasına vesile olmuştur. Sanat diğer disiplenlerle de ilişki içerisindedir. Örneğin felsefi metnin okunabilirliği ile edebî metnin okunabilirliği aynı değildir. Sanat burada devreye girerek bilim ve felsefe gibi alanların dengeleyicisi / tamamlayıcısı olmakta ve kısacası hayatı hayatın içinden anlatmaktadır. İlk Çağ’dan beri felsefe ve sanatın iç içe ve etkileşim halinde olması, yalnızca sanat eserlerine bakılarak düşünce tarihinin gelişiminin izlenebilmesini mümkün kılmaktadır (Kale, 2014, s. 72). Birçok olgu ve düşüncenin biraraya gelmesi ile sanat eserinin dişa vurumu gerçekleşmektedir. Dışa vurulan her çalışmanın sanat eseri olmadığı aşîkardır. Bir eserin sanat eseri olarak tanımlanabilmesi için belirli bazı kriterlere uygun olması gerekmektedir. En genel haliyle Kale sanat eserini şu şekilde özetlemiştir: “. .. insan eliyle oluşturulmuş temelde insanlar üzerinde estetik hazlar (heyecanlar; tepkiler) uyandırma işlevi olan yapıttır.” (Kale, 2014, s. 72). Eserin ortaya çıkma sürecinde ise 
sanatçının bilinçaltı, nöronları arasındaki bağlantı, gözlem yeteneği, hayal gücü, geçmiş yaşantısı gibi unsurlar devreye girmektedir. Ancak makalenin kapsamı gereğince bu unsurlar sinırlı tutulmuştur.

Her insanın kendisini anlatma gayesi içinde olduğu aşikardır. Kimi insan içinde biriktirdiklerini basit sözcükler kullanarak dışarıya aktarırken, kimisi de bunu sanatıyla yapar. Zihinde birikenlerin dışavurumu gerçekleştikten sonra zihin rahatlar. Hemen her insanın günün her anında yaşadığı bu dışavurum arzusunu Emre şu ifadelerle anlatııştır:

Zihnimde birtakım imgeler belirir. Bana ait ifadeler. Yalnızca bana. Benim olan duygusallıkların bir hayale, sadece bana yönelik olarak bilincimde kurgulanması... Kendine dönük hissedişler, belirip kaybolur, belirip kaybolur. Sonra bunları paylaşmak isterim. Paylaşmak. Yapılan hep budur. Sürekli benden, bilinç dışımdan çıkıp dışarı atılmak isteyen, atıldığı zaman beni rahat ettiren bir istek. Bunun yolu ifade etmektir. İfade edince rahatlarız. (Emre, 2014, s. 30)

Aynı şekilde Kale de Felsefiyat adlı eserinde Croce'yenin düşüncelerine yer vererek ifade edilmeyen şeylerin yalnızca duyum olarak kalacağını ve sezgiye dönüşemeyeceğini yani sanat eserinin ortaya çıkamayacağını belirtmiştir (Kale, 2014, s. 74). Bunun yanında ortaya çıkartma sürecinin bir de bilincin sınırlarının dışında yer alan bilinçaltı boyutu mevcuttur. Tolstoy'un eserinde belirttiği üzere Helmholtz da güzelliği bilinçaltında aramış ve sanatçının bilinçaltını analiz etmiştir (Tolstoy, 2004, s. 96). Emre de benzer ifadelerde bulunmuştur: “Aklın bilinçdışı oyunu, düşlerde ve sanatlarda ortaya çıkar.” (Emre, 2014, s. 52). Gourmont “Düşüncenin bilinci, düşünce değildir” (Gourmont, 2011, s. 32) demiştir ve düşünülen şeye bilinçli bir şekilde odaklanılırsa sağlıklı düşünülemeyeceğine vurgu yapmıştır. Gourmont’un "Altbilişsel hal, tam bir erkinlikle cereyan eden otomatik beyinleşme bilincinin sınırında, biraz altta ve onun etkisinden uzak kalarak, gelişen anlıksal etkinliktir.” (Düşünce Oluşumu, 2011, s. 32) ifadelerinden anlaşılacağı üzere bilincinde olmadığımız düşünme hali müdahalesiz anlık olarak gerçekleşir ve dişavurumu yıllar sonra bile gerçekleşebilmektedir (Düşünce Oluşumu, 2011, s. 32). Gourmont mucitlerin iyi bir gözlemci olmalarının yanında imgeci de olduklarının altını çizmiştir (Düşünce Oluşumu, 2011, s. 33). Gourmont eserinde Schopenhauer'ın altbilişselin durmaksızın çalışarak emek harcamasını geviş getirmeğe benzettiği ifadelerine yer vermişti (Düşünce Oluşumu, 2011, s. 35). Bu benzetmeye göre fikirler olgunlaşmaya bırakılırlar ve hazır olduklarında ortaya çıkarlar. Bilinç ile bilinçsiz hal etkileşimde bulunurlar. Gourmont da bu süreçte rüyaların önemine dikkat çekmektedir. Bilinçaltının ortaya çıktığı 
mecralardan bir tanesi de rüyalardır ve rüyalarda düşünme eylemi devam etmekte, hatta yarım kalmış eserlerin sonu getirilmektedir (Gourmont, 2011, s. 39).

Bir Aktör Hazırlanıyor isimli eserinde Yönetmen Torstov ile olan anılarını anlatan Stanislavski, Torstov'a ait şu sözleri aktarmıştır: “... bu son derece karmaşık, yaratıcı bir çalışmayı gerektirir. Karmaşık yaratıcı çalışmaysa, bir dereceye kadar bizim bilincimizin denetimi altında oluşsa da, daha önemli oranda bilinçaltında ve isteğe bağlı olmadan meydana gelir... Bilinçaltı, sezgi, çalışmamıza sokulunca da ona nasıl karışmayacağımızı bilmeliyiz.” (Stanislavski, 2013, s. 29). Yönetmenin sözlerinden anlaşılacağı üzere, tıpkı yukarıda sözü edildiği gibi, buz dağının görünmeyen kısmı olan bilinçaltının durmaksızın çalışmakta olduğunun altı çizilmiştir. İsmet Emre ise Edebiyat Bilimi adlı eserinde belirttiği üzere DabreyTownsend'e göre hayal gücü ve bilinçaltı yaratma sürecinde beraber çalışmaktadır (Emre, 2014, s. 51).

Başka bir konuya gelecek olursak bir eserin anlamının yazarın zihninde, eserin kendisinde ya da okurda aranması gerektiği sorunsalı günümüzde hala daha devam etmektedir. Eleştirmenler görünenin ötesindeki anlamı ortaya çıkartma amacında olsalar da, her yeni çağ kendisiyle birlikte yeni anlamlar yaratmaktadır. Edebiyat Kuramları ve Eleştiri adlı eserinde yer alan şemada Berna Moran, toplum, sanatçı, eser ve okuru hepsinin birbirinden beslendiği; bir tanesi eksik olursa düzenin bozulacağı, bu unsurların bir bütünün parçaları olduğunu belirtmiştir (Moran, 2012, s. 10). Özeskici’ye göre alıcı ve sanatçı arasındaki diyaloğu belirleyen etmenler eserdeki kavramsal unsurlar ve sorgulamalardır (Özeskici, 2018, s. 9). İlişkilerin yanında İnal da ilerleyen satırlarda sanat eserinin sanatçı ve yorumcu bakış açılarında nasıl farklılaştığını ifade etmektedir:

İster resimde, ister müzikde, ister yazında olsun, hep aynı iç sıkıntısı, aynı karamsarlık belirliyor sanat yapıtlarını. Sanatçıya gelince o, kuğuların yüzdüğü gölü çevreleyen uçsuz bucaksız ormanda doğayı dinliyor, doğanın gizemci müziği, uyumu ile duyuüstü gerçeğe ulaşmanın tadını çıkarıyor. Duygularını kapalı, bilmecemsi bir dille anlatırken, estetik değerini önemli bulduğu görme, işitme, tat alma duyularını sanat yapıtının oluşmasında ana gereç olarak kullanıyor. (İnal, 1981, s. 169)

Yazarı merkeze koyan yorumcular sanatçının kafasının içinden geçenler bilinirse eğer eserin daha doğru yorumlanacağına inanılmaktadır. Ancak sanatçının yaşamının bir döneminde yaşadığı kötü bir olayın eserine kattığı karamsar havanın sebebi olarak tespit edilmesi eserinin sanatsal değeri hakkında bilgi vermemektedir (Moran, 2012, s. 134). Yaratma ve yorumlamanın ortak yanı sürecin önce içeride başlayıp sonra dışarıya taşmasıdır. 
Sanatın toplum için ya da sanatın sanat için olduğunu savunan birbirinin karşıtı iki farklı görüş mevcuttur. Birinci görüşü savunanlara göre sanat, toplumsal gerçeklerin sanatsal imgelerle yansıtılmasıdır. Amaç güzeli değil gerçeği betimlemektir. Özellikle Sanayi Devrimi'nden sonra modern dönem ile birlikte sanat, alıcı, eser ilişkisi kuvvetlenmiştir. Çünkü sanat soyluların tekelinden çıkıp toplumla kucaklaşmıştır (Özeskici, 2018, s. 6). İkinci görüşe göre ise sanat estetik haz içindir. (Tezcan, 2018, s. 44-45). Ancak zaman içersinde, dünya savaşlarının da etkisiyle, estetikten toplum tabanlı yaklaşımlara geçilmiştir (Özeskici, 2018, s. 5).

\section{Sonuç}

Sanata duyulan ihtiyaç neredeyse insanın +1 değer kazanarak farklılaşmaya başladığı sürece tekabül etmektedir. Hemen her dönemde hem eserini ortaya koyan sanatçı hem de eserin alıcısı bireyler sanata gerek estetik hazlar gerekse de yaşama anlam arayışı için ihtiyaç duymuşlardır. Çünkü sanat eserleri insanların baş edilmesi zor dış dünya koşulları yüzünden bozulan iç dengelerine kavuşmalarına yardımcı olmaktadır. İlk Çağ' da başlayan sanat serüveni insanla birlikte büyüyüp gelişmiş ve çeşitlenmiştir. Sanatın çok işlevli olması kadar, sanat eserinin ortaya çıkma süreci ve yorumlanması da bireyin bilişsel yapısı ve içinde yaşadığı çağın koşulları gibi içsel ve dışsal pek çok etmenin bir araya gelmesi ile gerçekleşmektedir.

Eserin ortaya çıkma sürecinde, sanatçının nörolojik farklılıkların yanı sıra kendi iç ve dış dünyasında tecrübe ettiklerini hayal gücü ve farklı görsel araçları harmanlayarak dışa vurmaktadır. Yorumlanması sürecinde de yaratma sürecinde görülenler ile benzelikler görülmektedir. Bu süreçler beraberlerinde estetik kavramının ortaya çıkmasına zemin hazırlamışlardır. Estetik algısı gelişmiş insanların sahip oldukları yetinin doğuştan gelen bir eğilim olduğu nörolojik çalışmalar sonucunda ortaya çıkmıştır.

İşlevsel olarak bakıldığında eser üretmenin zamanın ve bireyin ihtiyaçlarından doğduğu görülmektedir. Hissedilen ihtiyaç toplumsal koşullara göre değişiklikler göstermiştir. Her toplum ve toplumsal olay kendi sanatçısını ve beraberinde eserini yaratmaktadır. Picasso ve bir Alman general arasında geçen diyalog bu yargıyı daha somut hale getirecektir: Alman general, Alman ordusunun Guernica'yı bombalamasının anlatıldığı eser olan Guernica' yı işaret ederek eser sahibi Picasso'ya bu resmi siz mi yaptınız diye sorar, aldığı yanıt oldukça anlamlıdır: "Hayır siz yaptınız."

Her sanat dalının kendi dili ve her sanatçının değişik dışa vurma biçimleri vardır. Sanat eserinin ortaya çıkma serüveni insandan insana, toplumdan topluma, çağdan çağa değişiklik göstermektedir. Sanat hayatta kalmak için gerekli olmamasına rağmen; hemen her dönem ve 
topluluk tarafindan ihtiyaç duyulmuştur, duyulmaktadır. Sanatı, sanatçıyı ve süreci anlamak uzun soluklu bir süreçtir.

\section{Kaynakça}

Bazin, G. (1998). Sanat Tarihi. (Ü. Ünal, \& S. Hilav, Çev.) İstanbul: Sosyal Yayınlar.

Bozkurt, N. (1994). Eleştiri ve Aydınlanma. İstanbul: Say.

Emre, P. D. (2014). Edebiyat Bilimi. Ankara: Anı yayıncılık.

Fagan, B. (2019). Cro Magnon: Buzul Çă̆ı İlk Modern İnsanı Nasıl Yarattı? (N. Soysal, Çev.) İstanbul: Say Yayınları.

Gourmont, R. D. (2011). Düşünce Oluşumu. (M. Özdil, Çev.) İstanbul: Kumsaati Yayınları.

İnal, T. (1981). Simgecilik. Yazın Akımları Özel Sayısı (s. 168-186). içinde Ankara: Türk Dil Kurumu.

Jacobs, R. H., \& Cornelissen, F. W. (2017, Mart 2). An Explanation for the Role of the Amygdala in Aesthetic Judgments.

Kale, N. (2014). Felsefiyat. Ankara: Pegem Akademi.

Kandel, E. (2012, Ağustos 10). Scientific American. Şubat 1, 2020 tarihinde https://www.scientificamerican.com/article/age-of-insight-excerpt/ adresinden alınd1

Moran, B. (2012). Edebiyat Kuramları ve Eleştiri. İstanbul: İletişim Yayınları.

Özeskici, E. (2018). Sanatta Değişen Paradigmalar: Sanatçı, Eser ve Alıcı İlişkisi.

Sheikh, K. (2019, Mayıs 22). Scientific American. Şubat 1, 2020 tarihinde https://www.scientificamerican.com/article/creative-types-reserve-a-special-corner-ofthe-brain-for-dreaming-big/ adresinden alındı

Stanislavski, K. (2013). Bir Aktör Hazırlanıyor. (S. Taşer, Çev.) İstanbul: Pegasus Yayınları.

Steenberg, E. (2007). Visual Aesthetic Experience. University of Illinois Press.

Tezcan, P. D. (2018). Sanat Sosyolojisi Giriş. Ankara.

Tolstoy, L. N. (2004). Sanat Nedir. (A. B. Dural, Çev.) İstanbul: Bilge Karınca.

Türk Dil Kurumu. (tarih yok). Türk Dil Kurumu Sözlükleri. Aralık 1, 2019 tarihinde https://www.sozluk.gov.tr/ adresinden alınd1

Urgan, M. (2018). Ingiliz Edebiyatı Tarihi. İstanbul: Yapı Kredi Yayınları.

Vessel, E. A., Starr, G. G., \& Rubin, N. (2012, Nisan 20). The brain on art: intense aesthetic experience activates the default mode network. ResearchGate: https://www.researchgate.net/publication/224821928_The_Brain_on_Art_Intense_Aes thetic_Experience_Activates_the_Default_Mode_Network adresinden alınd 1 


\section{Summary}

\section{What is Art? Who is Artist?}

A human is a living being that is aware of his/her existence. People try to make their lives livable by adding meaning to their lives. These meanings vary from individual to individual, from society to society, from age to age. However, another feature that distinguishes the human being from other living things is the existence of an understanding of art, among others. Although there have been different definitions of art in different periods across the globe, its essence is clear. Art, in general terms, is an individual's way of self-expression by using language, lines and forms. Each branch of art has different forms of expression. However, that does not mean that every individual work is a work of art. On the other hand, the debates on whether art is for art's sake or for society continue from the past to the present. Art has been performed in every community in every period with the first man in the universe. The creation of art needs not only the artist but also the individual, the beneficiary. The first known works of art in the history of humanity are believed to be paintings made on the cave walls in the Palaeolithic period. The aim of the people living in that period was not to create a work of art. As stated above, art is derived from the individual's need to express what s/he experiences and observes. The paintings made in the caves are also mirrors of what happened in that period. As the cognitive skills of the people living in the Paleolithic period improved, the works that reached today began to emerge. There are different interpretations of these works. However, we will never be able to find out why they were made although there are strong assumptions. As for who the artist is, it has no simple answer. Yet more or less a person who deals with any branch of art among people is defined an artist. What is more, an artist is a person who witnesses the age s/he lives in, guides in his/her time as well as in the future and senses the responsibility for the society.

\section{The Process Of Creation Of The Work Of Art}

Human beings are in an effort to understand and make sense of the world in which they live. The effort to understand life paved the way for philosophy, and the effort to make sense of the art. Art interacts with all other disciplines. A work of art emerges with the combination of many facts and thoughts. In order for a work to be defined as a work of art, it must meet certain criteria. Many factors such as the subconscious of the artist, the communication between his/her neurons, the ability to observe, his/her imagination, and his/her past are factors in the creation process of the work of art. Human being needs to express him/herself. Each individual's 
method of expression is different. While some express themselves only by speaking, others may express themselves with their art. These expressions in the mind first mature in the subconscious, then the expression takes place. This maturation process can sometimes take years. According to some opinions, the subconscious and imagination work together in the process of creating. Dreaming is a mental activity. People of all ages consciously or unconsciously dream at any time of the day. Imagination is necessary both in the creation process of the work of art and helps individuals escape from the flow of daily life, albeit temporarily. It is not possible for a work of art to emerge without imagination. Our bodies are limited, but minds are unlimited. The biggest supporter of the artist is the ability to dream and imagine. Artworks, which are the products of imagination, also activate the mental activities of the recipient. Each work of art is unique and cannot be repeated. And all works have a meaning. The debates that the meaning of the work should be sought in the mind of the author, in the work itself or in the mind of the reader continue today. The society, the artist, the reader, and the work all feed each other. Some critics put the author at the centre. They argue that if the writer's mind is known, the work will be understood better. However, artists oppose this view out of concern that their private lives will be exposed. According to those who defend that art is for society, art should reflect social realities with artistic images. According to those who argue that art is for art's sake, art is for aesthetic pleasure. Whatever the reason is believed to be, art is a need to be met. 